\title{
Fault detection and power quality analysis of wind turbine system using integrated systems
}

\author{
Anburaj Mutharasan, Perumal Chandrasekar \\ Department of Electrical and Electronics Engineering, Vel Tech Rangarajan Dr. Sagunthala R\&D Institute of Science and Technology, \\ Chennai, India
}

\begin{tabular}{l} 
Article Info \\
\hline Article history: \\
Received Sep 28, 2021 \\
Revised Jan 27, 2022 \\
Accepted Feb 3, 2022 \\
\hline
\end{tabular}

Keywords:

Fault analysis

Gearbox

Power quality

Vibration

Wind energy

\begin{abstract}
Growth in the need for electric energy and fossil fuel scarcity endorses renewable energy generation sources. The generation cost of electric power utilizing wind turbines is cost-effective and straightforward compared to other renewable energy sources (RES). Recently, hasty research and developments have been presented in wind turbines (WT) by researchers globally. Although wind-based energy production is more content, planting the WT is challenging. Maintaining the WT from fault incidence is highly crucial. The fault in the WT distresses the power quality of the produced energy. This condensed power quality affects the transmission systems, substations, and loading end of the renewable source. Also, gear malfunctioning is the primary reason for most of the downtime in wind turbines. This work successfully proposed and implemented a deoxyribonucleic acid (DNA) sequencing-based control technique to reduce the drive train vibration. Therefore, fault detection and monitoring in WTs play an active part in power production and quality maintenance. In this work, a vibration-grounded WT gearbox fault observing scheme is proposed to increase the power quality. Precisely, a wavelet is executed to chart the vibration gesture. Also, the current sensor gesture is implemented to discover the power quality variances associated with the WT's vibration magnitude.
\end{abstract}

This is an open access article under the CC BY-SA license.

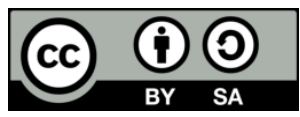

\section{Corresponding Author:}

Anburaj Mutharasan

Department of Electrical and Electronics Engineering, Vel Tech Rangarajan Dr. Sagunthala R\&D Institute of Science and Technology

Avadi-Vel Tech Road, Poonamallee-Avadi High Rd, Vel Nagar, Chennai, Tamil Nadu 600062, India

Email: mutharasanm@gmail.com

\section{INTRODUCTION}

Increasing electricity consumption chiefly generated by burning fossil fuels leads to numerous environmental and economic issues [1]-[3]. Moreover, countries worldwide enhance their installed renewable energy potential using solar plants and wind farms [4]. In developing renewable energy sources (RES), wind potential shows a vibrant role in power generation [5], [6], significantly reducing fossil fuel production. The expertise adapted in wind power production is a critical exploration undertaken globally, and numerous growths are presented to exploit wind power efficiently [7]-[9]. Even if innumerable enlargements have been demonstrated in the wind turbines (WT), they are significantly exposed to physical destruction, chiefly due to gearbox letdown.

The WT encompasses various fragments in which the gearbox concede the most extended downtime, and the maintenance price is too large. Therefore, prompt revealing of a letdown in the gearbox could decrease the prospects of catastrophic breakdown in the WT. Thus, the researchers are concentrated on 
developing fault identification approaches to diminish the gearbox's lost time that upturn the WT's consistency. The coating is applied to the gearbox to lift the pitting error in the gearing arrangement. The gearing system is fixed to run at a lesser phase when a bearing difficult is recognized; erstwhile, it can be adapted to accomplish the maintenance exertion. The gearbox arrangement is located between the core and generator, and it can be adapted to change the low-phase great torque revolution power to high-phase lesser torque power requirement for the generator component to produce electric energy. The WT is chiefly encompassed of gears, bearings, and shafts. Also, the fault is observed, and the diagnosis scheme is intended to avoid faults in the rotating mechanisms in the WT to upturn the efficacy of wind energy production. The WT's power quality chiefly hinges on the influences upsetting the turbine behavior. These faults induced in the parallel WT affect the power quality that could distress the enactment of the grid coordination.

In conventional gearbox-activated WTs, the blades twisted the shaft coupled to the gearbox arrangement and followed to generator [10], [11]. The gearbox changes over the revolving phase of the cutting edge between $15 \mathrm{rpm}$ to $20 \mathrm{rpm}$ into around 1,800 rpm for a 1 megawatt (MW) WT that produces maximum power. It makes the gearbox the highest upkeep of a turbine [12]. The compound bearings and wheels in a gearbox endure enormous stress due to wind turbulence, and the turbine would halt if there is any fault in a single component. The gearboxes in offshore WTs which face high-speed wind are more susceptible than onshore WTs.

\section{LITERATURE SURVEY}

The power quality issues and fault detection in WT can be performed using various schemes and methodologies; some of the recent literature reports are illustrated in Table 1 (seen in Appendix) [12]. Based on the literature survey, this work aims to obtain crucial objectives mentioned as shown in Table 1. Objectives; i) to reduce the drive train vibration of the wind turbine system, ii) to Interface vibration and current sensors into the WES, iii) to analyze the performance using different modes such as manual, step-bystep, and power 2 mode, iv) to study the coefficient of the module, angle coefficient, and module coefficient lines, and v) to evaluate the harmonic content at different frequency spectrums.

\section{METHODOLOGY}

Various expertise is presented to examine and identify the faults engendered in WTs to raise the power quality of wind energy production. Specifically, observing vibration signals, auditory discharge, and oil feature examination extensively finds WT-scale faults. Amongst these practices, vibration and auditory release shows a vigorous character and offers supreme efficacy for the fault detecting schemes for the WT gearbox.

\subsection{Vibration examination}

It is an utmost operative method in recognizing faults in WT gear schemes. It offers higher precision than other methods considered for fault computation in the gearbox. The vibration-revealing practice needs only a modest electronic assembly to record and observe the gearing system's vibration gesture. Further, enhancement in the signal processing procedures aids in detecting faults even in the prior period. It can be accomplished in diverse modes such as online, offline, and episodic statistics from the analyzing scheme.

\subsection{Oil analysis}

It is executed to detect lubricant situations, wear (mechanical outward), and lubricant oil impurity. Due to conditional deviations in the lubricant oil quality, the arrangement behavior will be pretentious. Therefore, an oil investigation is accomplished to find the lubricant disorder to avoid the system letdown. It is implemented in the gearbox segment of the WT since the lubricant is adapted only for the mechanical revolving expedients. This system is directly fitted in a gear mechanism to display the oil pollution and deprivation. Owing to the rubbish of metallic matters produced by bearing mechanism and gear fault, lubricant oil can be contaminated. Evaluating the debris material sizes in oil aids in discovering the deterioration range. Further, defects owing to pitting in gear exterior can be efficiently recognized. However, detecting the fault place is improbable over the oil investigation.

\subsection{Acoustic discharge}

It employs robust sensors to capture the audio produced from the WT. The difference in the production of noise owing to a fault in the WT can be proficiently examined. To illustrate the fault audio signal from the ecological sound, signal processing procedures are employed [25], [26]. To improve the precision of the acoustic production, this practice is united with other fault observing methods, specifically vibration examination, current signature study, or oil investigation practices. 
The fault produced in WT decreases the system behavior and diminishes the power produced from the WT. It distresses grids and connected loads unswervingly associated with the wind energy system and deprives power quality upturn the transmission line losses. To alleviate these glitches, a vibration-based fault observing scheme is presented. An incessant 1D wavelet examination is employed from the logged vibration sign, and the disintegrated outcome is associated with the interpretations gathered from the current transformer, specifically at the demand end. The disintegrated effects of vibration characteristics and current transformer signs are related to investigating the system WT power quality. The functional block illustration of the suggested approach is illustrated in Figure 1. WT is coupled to the gearbox system, and it changes lowphase, more significant mechanical torque to high-phase, small mechanical torque. The gearbox output is given for the generator, and energy produced through the generator is transported to the load side.

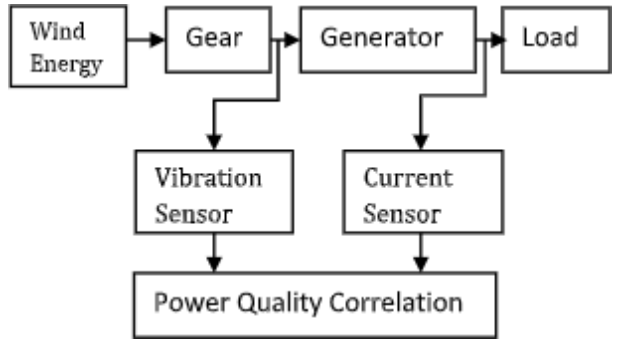

Figure 1. Block diagram of the proposed system

The vibration magnitude of the gearing scheme is logged by the ADXL620 (sensor) and then given for the power quality association, and respective vibration magnitude is related with the current sensor rate to sketch the power quality trouble grounded on the fault persuaded in the WT. Further, a multifaceted 1D wavelet transform is adopted to examine the input signal. The logged gearing vibration signs are further problematical; therefore, wavelet study is essential to execute fault analysis. They are adapted to calculate periodicity and influence mechanisms of the input signal. Also, it produces greater time resolve and minor frequency profile in higher frequency need; small-frequency fragments can make lesser interval resolve in the upper-frequency dominion.

The purpose of wavelets is termed as $\Phi(\mathrm{t})$, which is equal to the integration of square function, $\Phi(\mathrm{t})$ $€ \mathrm{l}^{2}(\mathrm{R})$, and the procedure contains the (1). Also, the incessant wavelet transmute task $\mathrm{f}(\mathrm{t})$ grounded on the above-illustrated wavelet task is represented (2).

$$
\begin{aligned}
& C_{\Phi}=\int \frac{|\Phi(\omega)|^{2}}{\omega} d w<\infty \\
& W T_{f}(a, b)=\left[f(t), \Phi_{a, b}(t)\right] \\
& =\frac{1}{\sqrt{a}} \int_{R} f(t) \Phi^{*}\left(\frac{t-b}{a}\right) d t
\end{aligned}
$$

Where $\Phi^{*}$ is the complex conjugate $\Phi ; \Phi_{a, b}(t)=\Phi\left(\frac{t-b}{a}\right) d t$ is the essential function that hinges on the constraints a, b. Wavelet examination is employed for a gearbox fault recognition and power quality regulator that undertakes the subsequent steps Figure 2.

\subsection{Fatigue load calculations and power quality analyzer}

This work also recommended a deoxyribonucleic acid (DNA) sequencing algorithm, attaining a wise and more detailed examination of harmonics in the control schemes. The conventional audio evaluation and computation methods have been adapted combined to develop other productive approaches for the harmonic investigations that can accept needs of better proficiency, excellent evaluation, and dispensing with constraints of conventional arrangements up to an unprecedented scale. A current transformer is employed for converting current from a higher magnitude into a proportionate lesser scale current, and henceforth, it is adapted to convert the high voltage-current to low voltage-current. Hence, the higher rate of current feed through the transmission line Figure 3 happens in the system. 
In this fragment, a synthetic discussion of the DNA sequencing algorithms has been adapted to evaluate genomically. There are three stages in the DNA sequencing algorithm in genomic sequences as signal plotting, discrete fourier transform (DFT), and PPS plotting. During the accomplishment of fragment collections, it has been sequenced and equating the same of all the fragments that will expose and end with convergence using other fragments. In this framework, the several identical segments with an original signal are segregated and then sampled into random places. The considered several identical signals end up by attaining various fragment lengths. The complete sequences from one side of the original DNA to the other can be compiled by providing the sequence from the first to the last overlapping fragment. It is stressed that genome sequencing is the extent advanced in comprehending signal processing, and it has vast potential for signal diagnosis and treatment.

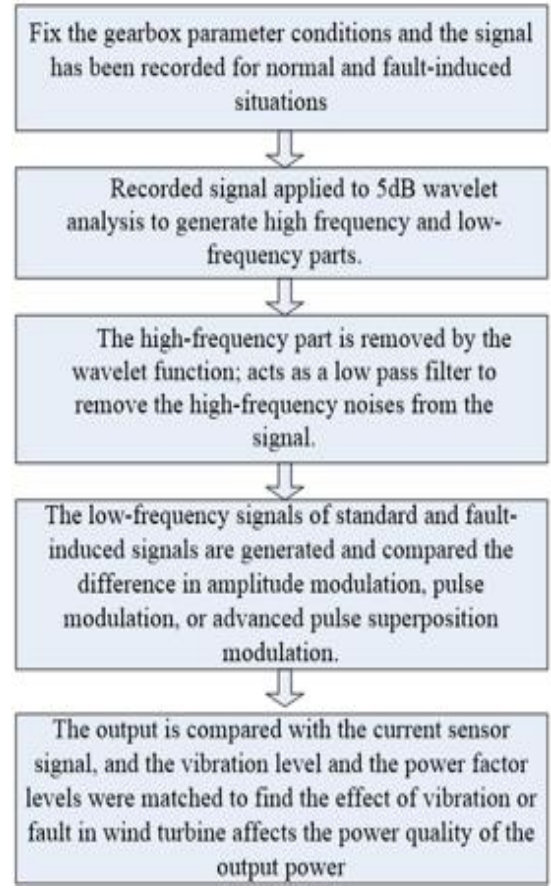

Figure 2. Steps involved to evaluate the fault

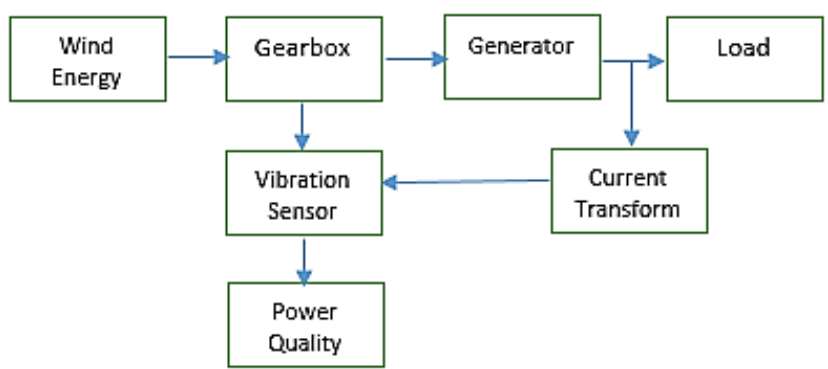

Figure 3. Block diagram of the proposed methodology

\section{RESULT AND DISCUSSION}

The signals received from the vibration sensor and current sensor are logged through the WT gearbox and demand end. Their sampled signals are logged by means of sigview tool and it is given to the Matlab wavelet evaluator platform to execute multifaceted incessant wavelet conversion. Their input signal is given to the multifaceted incessant wavelet conversion to execute all operation modes shown in Figure 4. The sampled signals are composed and adapted in several diverse examination modes at multifaceted continuous wavelet conversion. There are three modes of examination: step by step mode, power 2, method, and manual approach. The outcomes of every single model are illustrated by the mean of the angle and module of the input signal. 


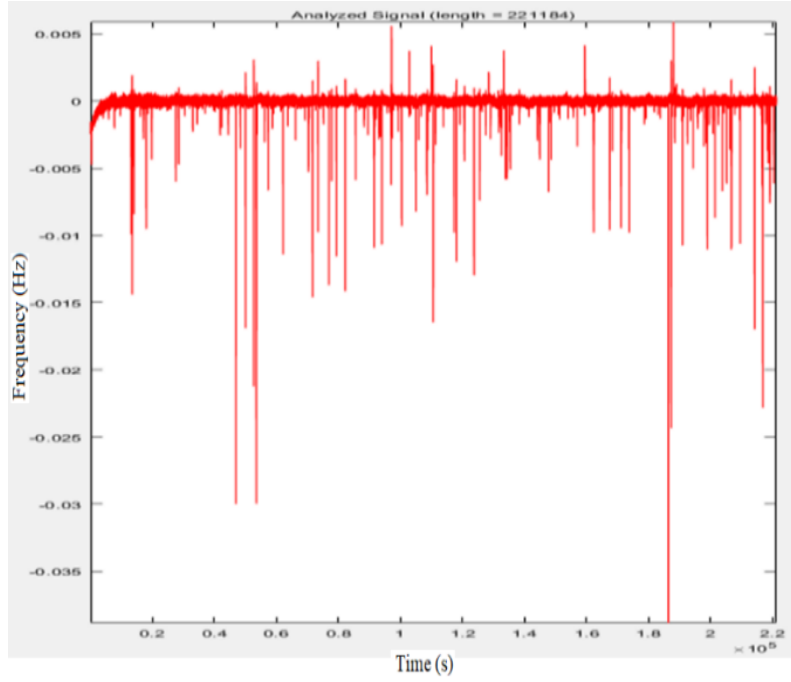

Figure 4. Analyzed input signal

The first mode, i.e., step by step, is examined wherever the disintegration ratio of wavelets is fixed at the sixth stage. Further, the module and the angle coefficients have schemed. Figure 5 (a) displays the module coefficient representing the minimum and maximum scheming of the input unit rate of an input gesture. Further, a peak value and designated module crest value are depicted through the image. Furthermore, Figure 5 (b) displays the angle coefficients for the variables for the step-by-step method. Also, the coefficient lines of the module for variables $a$ and $b$ are illustrated in Figure 5 (c), and its frequency is noticed as $0.009 \mathrm{~Hz}$.

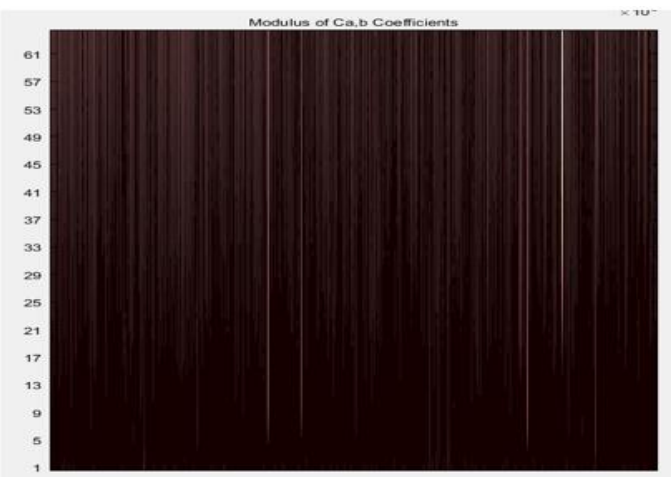

(a)

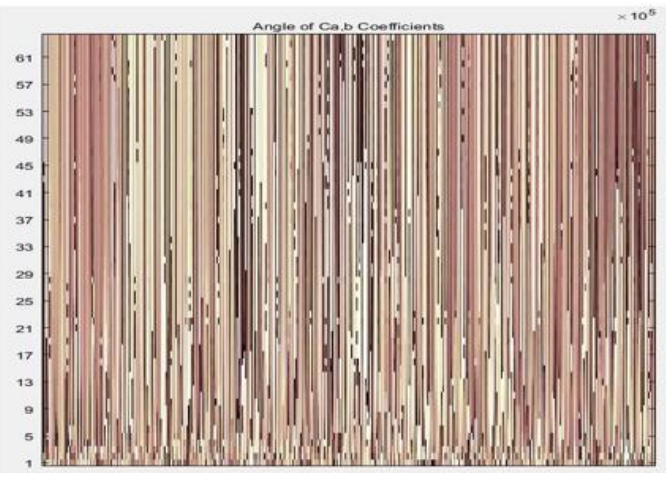

(b)

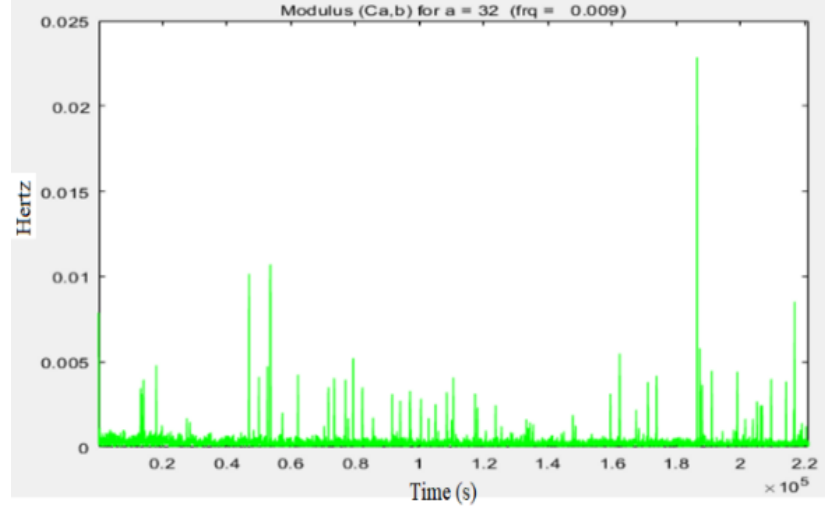

(c)

Figure 5. Step by step method (a) coefficient of module, (b) angle coefficients, and (c) module coefficient lines versus time (seconds) 
The module coefficient and its angle are stimulated by power 2 mode, and their outcomes of different modes are presented in Figure 6 (a) and Figure 6 (b), i.e., module coefficient and angle coefficient, respectively. Also, the lines of the module coefficient are illustrated in Figure 6 (c), and it shows the minimum and maximum scales of the factors. The angle coefficient displays the extent of the input factor throughout the incidence array. It is fixed as eight, and the frequency is noticed as $0.0370 \mathrm{~Hz}$, better than the step-by-step method.

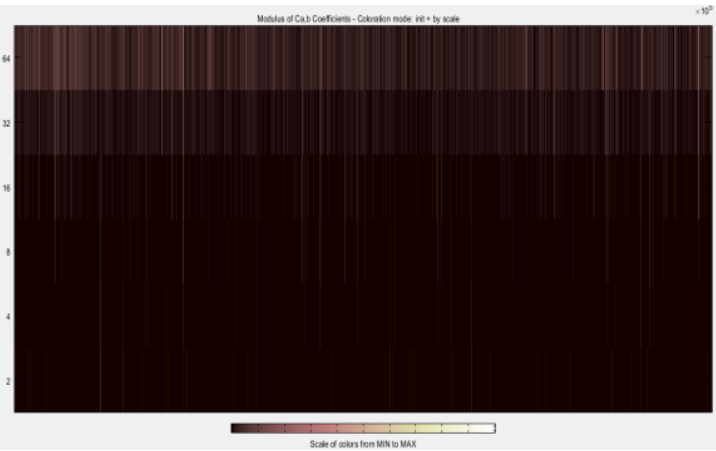

(a)

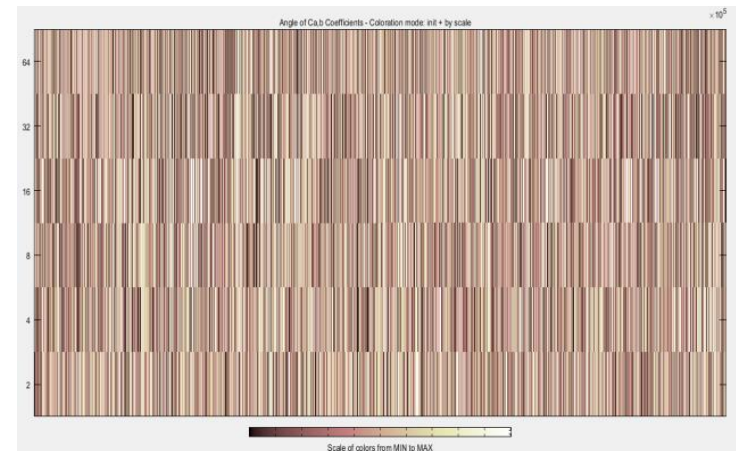

(b)

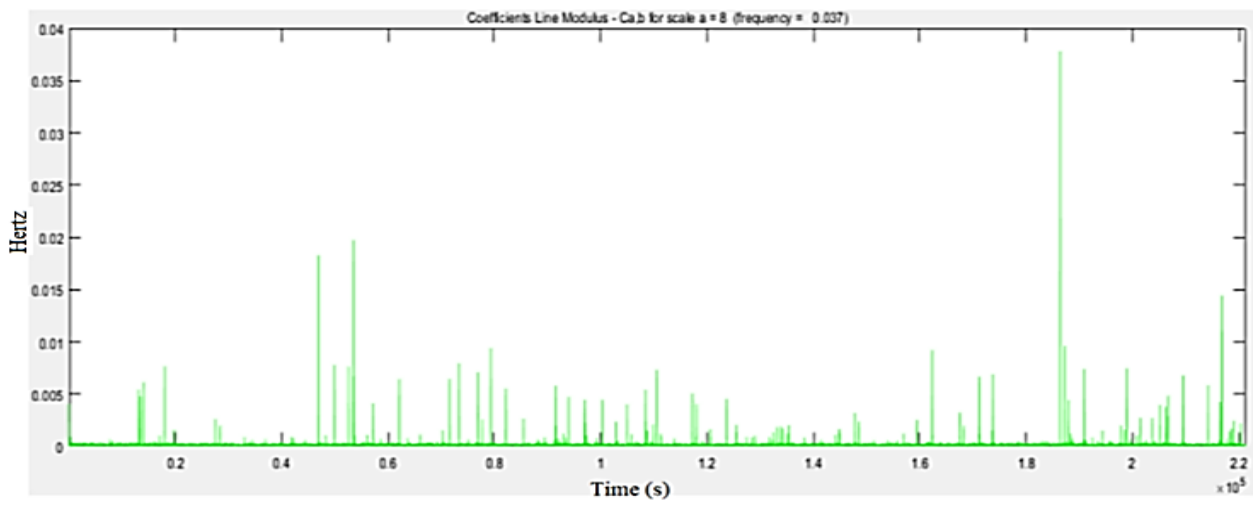

(c)

Figure 6. Power 2 mode (a) module coefficient, (b) angle coefficient, and (c) lines of module coefficient

Lastly, Figure 7 (a) and 7 (b) displays the association of different modules, angle factors of variables during the manual mode, and their scales are fixed as 01:01:64. Further, frequency is computed, such as $0.009 \mathrm{~Hz}$ from the line of module coefficient. Furthermore, Figure 7 (c) displays the result of the manual mode line of module coefficient for manual, and the mutable 'a' is set as 32. The investigation of module coefficient in each case, i.e., case 1 and case 2 (power module (PM)) is discussed in detail Table 2. The results show that the module coefficient of power module 2 shows a grander scale compared with power module 1. This detailed result exhibits a better module coefficient that can be adapted for further system planning.

Further, the vibration signals are sensed via the sigview simulation software to analyze the power quality of the generator. The dissimilar vibration signals phase is explored via the FFT Figure 8. Figure 9 illustrates the harmonic voltage of the high-phase signal and the total harmonics distortion has been exploited to recognize the fault that ensues in the generator donating to the worst or better voltage presentation. The harmonic voltage at the dissimilar frequency assortments such as $50 \mathrm{~Hz}, 150 \mathrm{~Hz}$, and 250 $\mathrm{Hz}$ is illustrated in Table 3. The harmonic voltage of the various signal speediness and data has been described in the table. 


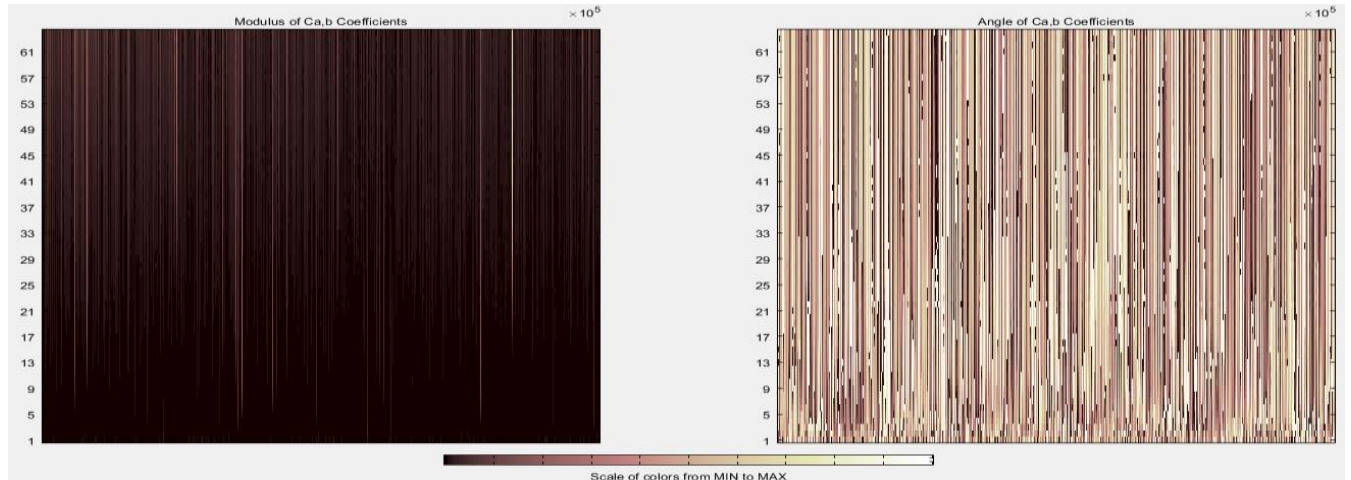

(a)

(b)

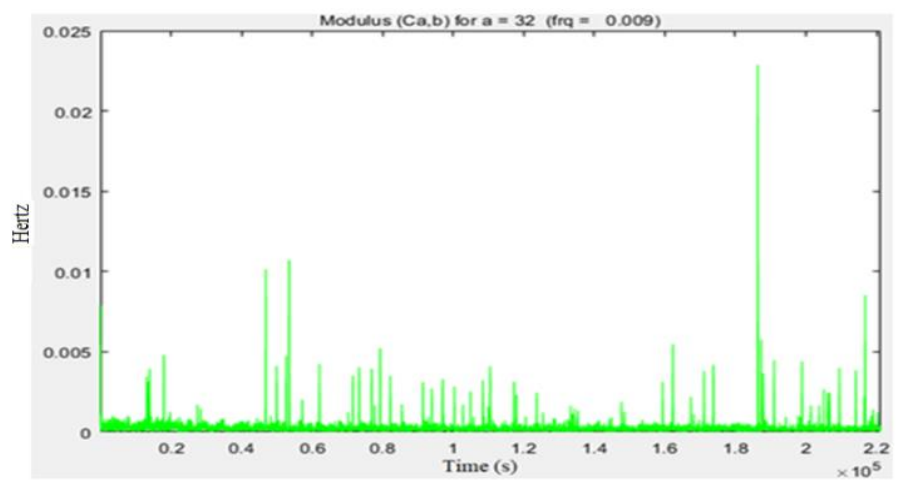

(c)

Figure 7. Manual modes (a) module, (b) angle coefficient, and (c) lines of module coefficient

Table 2. Simulated results for two different modules $(A=32)$

\begin{tabular}{cc}
\hline Module coefficient for two power module \\
\hline PM 1 & PM 2 \\
Frequency (Hz) $=0.09$ & Frequency (Hz) $=0.09$ \\
0.024 & 0.039 \\
\hline
\end{tabular}

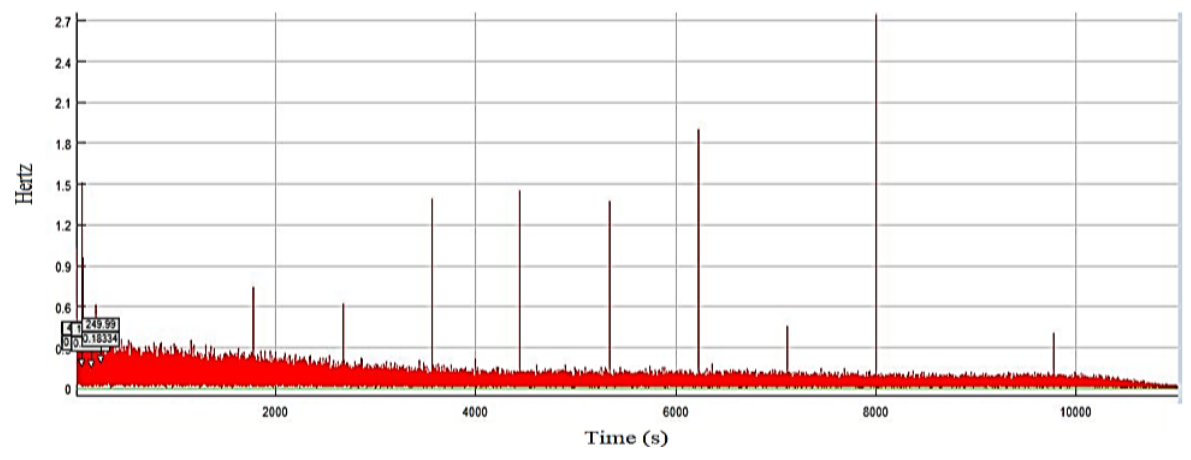

Figure 8. FFT analysis of a harmonics signal at high speed
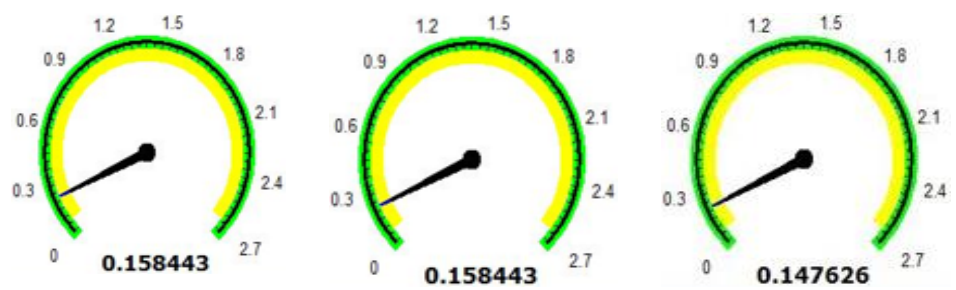

Figure 9. Harmonic voltage level of the high-speed signal (Hertz) 
Table 3. Harmonic voltages at frequency sort $50 \mathrm{~Hz}, 150 \mathrm{~Hz}$, and $250 \mathrm{~Hz}$

\begin{tabular}{ccccc}
\hline Signal type & Fourier power spectrum Range & $1^{\text {st }}$ Harmonic $(50 \mathrm{~Hz})$ & $3^{\text {rd }}$ Harmonic $(150 \mathrm{~Hz})$ & $5^{\text {th }}$ Harmonic $(250 \mathrm{~Hz})$ \\
\hline Ts & 2.2 & 0.553978 & 0.0387853 & 0.110852 \\
Ls & 3.0 & 0.0896189 & 0.0990269 & 0.0403476 \\
Ms & 1.9 & 0.391322 & 0.0214239 & 0.0319626 \\
Hs & 2.5 & 0.158443 & 0.147626 & 0.183337 \\
\hline
\end{tabular}

The work detected that the regression technique is a supreme crucial component to regulate power quality, i.e., for the power quality of the generator. Nevertheless, the regression scheme is helpful to analyze the power quality of the generator, and the magnitudes are associated with the ranges of the dissimilar vibration signals. Table 4 demonstrates the regression ranges for the power quality of the generator-the premeditated regression equivalence for the dissimilar harmonic arrays as stated as shown in.

$$
\begin{aligned}
& y=-36.5936(x)+117.250 \\
& y=7.8788(x)-11.9091 \\
& y=0.7576(x)+7.1818
\end{aligned}
$$

Table 4. Regression value for power quality analysis of the generator

\begin{tabular}{cccc}
\hline $\begin{array}{c}\mathrm{X} \text { value are the Fourier } \\
\text { power spectrum Range }\end{array}$ & $\begin{array}{c}\text { Y value are the } 1^{\text {st }} \\
\text { Harmonic at } 50 \mathrm{~Hz}\end{array}$ & $\begin{array}{c}\text { Y value are the } 3^{\text {rd }} \\
\text { Harmonic at } 150 \mathrm{~Hz}\end{array}$ & $\begin{array}{c}\text { Y value are the } 5^{\text {th }} \\
\text { Harmonic at } 150 \mathrm{~Hz}\end{array}$ \\
\hline 2.2 & 36.5936 & 5.42426 & 8.8478 \\
3 & 7.264 & 11.7273 & 9.4546 \\
1.9 & 47.5922 & 3.06062 & 8.62124 \\
2.5 & 25.595 & 7.7879 & 9.0758 \\
\hline
\end{tabular}

\section{CONCLUSION}

The effects of fault generation and power quality analysis are carried out through integrating operation. Based on the observed results, the following conclusion are made; a multifaceted unremitting wavelet transform is realized in the gearbox of the WT to examine the vibration signals and current signal from the respective current sensor associated with the demand side; three different modes of operation are performed: manual mode, step-by-step, and power 2 mode. The power 2 mode shows a better module and angle coefficient among these; the regression method is adopted to evaluate the power quality of the WT using different harmonic functions. It delivers better performance along with the vibration analyzing tool.

\begin{tabular}{|c|c|c|c|}
\hline Ref. No & Year & Methodology & Inferences \\
\hline [13] & 2019 & $\begin{array}{l}\text { Dynamic voltage restorer } \\
\text { (DVR) }\end{array}$ & $\begin{array}{l}\text { - Symmetrical and asymmetrical fault states were verified to enlighten the } \\
\text { power quality and agree with the IEEE nominal voltage standards. } \\
\text { - Wind energy production and operation of the dynamic voltage restorer were } \\
\text { done using the PSCAD tool. } \\
\text { - The observed outcomes exhibited the appropriate DVR applicability against } \\
\text { voltage sag and voltage swell circumstances. }\end{array}$ \\
\hline [14] & 2018 & $\begin{array}{l}\text { Time-domain finite element } \\
\text { simulations }\end{array}$ & $\begin{array}{l}\text { - WT actions, ecological load schemes, and regulated damping scales on the } \\
\text { fatigue life were evaluated technically. } \\
\text { - Considerable economic savings were acquired in the WT arrangement } \\
\text { adapting supplemental damping systems. }\end{array}$ \\
\hline [15] & 2020 & $\begin{array}{l}\text { Fractional order sliding mode } \\
\text { control (FOSMC) and } \\
\text { gravitational search algorithm }\end{array}$ & $\begin{array}{l}\text { - A total of three experimental and simulations case studies were } \\
\text { demonstrated to display the efficiency of FOSMC. } \\
\text { - Characteristics of FOSMC were associated with existing proportional- } \\
\text { integral control and sliding mode control. } \\
\text { - Simulation and experiment outcomes revealed that the FOSMC had quicker } \\
\text { time reaction, greater tracking exactness in steady and variable state wind } \\
\text { speed settings. }\end{array}$ \\
\hline [16] & 2018 & $\begin{array}{l}\text { FEM and Brown-Miller } \\
\text { strain-life method }\end{array}$ & $\begin{array}{l}\text { - Examinations were performed to assess the real fatigue life, lubrication, } \\
\text { local raceway harm, and vibration hastening. } \\
\text { - A total of } 3 \text { fatigue life evaluation techniques had unique advantages that } \\
\text { would mutually be regarded to enhance the bearing life computation } \\
\text { precisely. }\end{array}$ \\
\hline
\end{tabular}

\section{APPENDIX}

Table 1. Existing works related to fatigue detection and power quality of WECS 
Table 1. Existing works related to fatigue detection and power quality of WECS (continue)

\begin{tabular}{|c|c|c|c|}
\hline Ref. No & Year & Methodology & Inferences \\
\hline [17] & 2017 & $\begin{array}{l}\text { Conservative Power Theory } \\
\text { decompositions }\end{array}$ & $\begin{array}{l}\text { - It offered decoupled power and current loci for the inverter switch that } \\
\text { offered very supple, discerning, and influential functionalities. } \\
\text { - } \text { Real-time simulation tool was accompanied to assess the behavior of the } \\
\text { suggested control algorithm. } \\
\text { - This control practice is employed and authenticated in hardware-in-the-loop } \\
\text { (HIL) interfaced with Opal-RT and a TI DSP. } \\
\text { - The observed consequences validated the proposed power quality } \\
\text { augmentation control scheme and permitted eliminating passive filters that } \\
\text { contributed a more compacted, suppled, and consistent electronic execution. }\end{array}$ \\
\hline [18] & 2017 & Sliding mode control theory & $\begin{array}{l}\text { - The suggested scheme was considered to alleviate the torsional vibration of } \\
\text { the wind turbine system. } \\
\text { - This proposed arrangement augmented the life span of the wind turbines } \\
\text { effectively compared with other schemes. }\end{array}$ \\
\hline [19] & 2017 & $\begin{array}{l}\text { Pulse width modulation based } \\
\text { WECS }\end{array}$ & $\begin{array}{l}\text { - Proposed a hybrid passive filter arrangement for pulse width modulation } \\
\text { rectifiers in its place of prevailing filters. } \\
\text { - The effectiveness of hybrid passive filter was verified through } \\
\text { MATLAB/Simulink background against several operational settings and } \\
\text { related with LCL filter structure. } \\
\text { - A neuro-fuzzy controller (NFC) was also chosen to raise the behavior of the } \\
\text { PWM rectifier in DC bus voltage control in contradiction of disturbances } \\
\text { generated. }\end{array}$ \\
\hline$[20]$ & 2018 & Finite element model (FEM) & $\begin{array}{l}\text { - Torsional vibrations and fatigue damages were evaluated using rain flow } \\
\text { cycle counting, Palmgren-Miner damage rule, and } \mathrm{S}-\mathrm{N} \text { curves. } \\
\text { - Fatigue forecastings using the proposed arrangement were substantially } \\
\text { regarded with experimental fatigue results that ensured the efficiency and } \\
\text { relevancy of the anticipated framework. }\end{array}$ \\
\hline$[21]$ & 2017 & $\begin{array}{l}\text { Rotary valve-controlled pitch } \\
\text { system }\end{array}$ & $\begin{array}{l}\text { - Real-world loading compensation methodology was blended and } \\
\text { convoluted in the pitch arrangement to recompense for the exterior } \\
\text { indeterminate pitch loads. } \\
\text { - The suggested pitch scheme and load compensation methodology were } \\
\text { calculated using generator power flattening and control precision. }\end{array}$ \\
\hline$[22]$ & 2018 & $\begin{array}{l}\text { Wavelet Linear quadratic } \\
\text { regulator }(\mathrm{LQR})\end{array}$ & $\begin{array}{l}\text { - The anticipated framework was considered to diminish the blade vibrations } \\
\text { occurred in the wind turbine system. } \\
\text { - Proposed new wavelet regulator acquired considerable reduction in the out- } \\
\text { of-plane phase of the blades associated with PI controllers or standard LQR. }\end{array}$ \\
\hline [23] & 2021 & $\begin{array}{l}\text { Higher-order sliding mode } \\
\text { (HOSM) with space vector } \\
\text { modulation (SVM) }\end{array}$ & $\begin{array}{l}\text { - Examined the regulating framework of the output voltage of a WT, which } \\
\text { consists of a permanent magnet synchronous generator associated with an } \\
\text { inverter/rectifier. } \\
\text { - Presented striking topographies likely chattering-free characteristics of the } \\
\text { sliding mode. }\end{array}$ \\
\hline$[24]$ & 2020 & $\begin{array}{l}\text { Fuzzy logic controller and } \\
\mathrm{C}^{++} \text {code }\end{array}$ & $\begin{array}{l}\text { - Presented the wireless system for fault finding and observing based on } \\
\text { fuzzy logic technique using proposed scheme. } \\
\text { - Proposed system could early perceive the fault incidence on the machine } \\
\text { with a running time of } 1.721 \mathrm{~s} \text {. }\end{array}$ \\
\hline
\end{tabular}

\section{REFERENCES}

[1] V. S. S. Balaguru, N. J. Swaroopan, K. Raju, M. H. Alsharif, and Mun-Kyeom Kim, "Techno-Economic Investigation of Wind Energy Potential in Selected Sites with Uncertainty Factors," Sustainability, vol. 13, no. 4, p. 2182, 2021, doi: $10.3390 /$ su13042182.

[2] C. Venkatesan, R. Kannadasan, M. H. Alsharif, Mun-Kyeom Kim, and J. Nebhen, "A Novel Multiobjective Hybrid Technique for Siting and Sizing of Distributed Generation and Capacitor Banks in Radial Distribution Systems,', Sustainability, vol. 13, no. 6, p. 3308, 2021, doi: 10.3390/su13063308.

[3] C. Venkatesan, R. Kannadasan, M. H. Alsharif, Mun-Kyeom Kim, and J. Nebhen, “Assessment and Integration of Renewable Energy Resources Installations with Reactive Power Compensator in Indian Utility Power System Network,'” Electronics, vol. 10, no. 8, p. 912, 2021, doi: 10.3390/electronics 10080912 .

[4] R. Hidalgo-León, et al., "Energy Harvesting Technologies: Analysis of their potential for supplying power to sensors in buildings," 2018 IEEE Third Ecuador Technical Chapters Meeting (ETCM), 2018, pp. 1-6, doi: 10.1109/ETCM.2018.8580292.

[5] M. Anthony, V. Prasad, K. Raju, M. H. Alsharif, Z. W. Geem, and J. Hong, "Design of Rotor Blades for Vertical Axis Wind Turbine with Wind Flow Modifier for Low Wind Profile Areas," Sustainability, vol. 12, no. 19, p. 8050, 2020, doi: $10.3390 /$ su12198050.

[6] M. Anthony et al., "Autonomous Fuzzy Controller Design for the Utilization of Hybrid PV-Wind Energy Resources in Demand Side Management Environment," Electronics, vol. 10, no. 14, p. 1618, 2021, doi: 10.3390/electronics10141618.

[7] R. Krishnamoorthy, K. Udhayakumar, K. Raju, R. M. Elavarasan, and L. Mihet-Popa, "An Assessment of Onshore and Offshore Wind Energy Potential in India Using Moth Flame Optimization," Energies, vol. 13, no. 12, p. 3063, 2020, doi: 10.3390/en13123063.

[8] S. Subramanian, C. Sankaralingam, R. M. Elavarasan, R. R. Vijayaraghavan, K. Raju, and L. Mihet-Popa, "An Evaluation on Wind Energy Potential Using Multi-Objective Optimization Based Non-Dominated Sorting Genetic Algorithm III," Sustainability, vol. 13, no. 1, p. 410, 2021, doi: 10.3390/su13010410. 
[9] K. Mehmood et al., "Short term power dispatch using neural network based ensemble classifier," Journal of Energy Storage, vol. 33, p. 102101, 2021, doi: 10.1016/j.est.2020.102101.

[10] B. Boukhezzar and H. Siguerdidjane, "Comparison between linear and nonlinear control strategies for variable speed wind turbines," Control Engineering Practice, vol. 18, no. 12, pp. 1357-1368, December 2010, doi: 10.1016/j.conengprac.2010.06.010.

[11] B. Boukhezzar, H. Siguerdidjane, and M. M. Hand, "Nonlinear control of variable-speed wind turbines for generator torque limiting and power optimization," Journal of Solar Energy Engineering, vol. 128, no. 4, pp. 516-30, November 2006, doi: $10.1115 / 1.2356496$.

[12] S. Govindan and A. E. X. Santiago, "Optimized dielectric barrier discharge-plasma actuator for active flow control in wind turbine," Structural Control and Health Monitoring, Wiley, vol. 26, no. 12, pp. 1-17, October 2019, doi: 10.1002/stc.2454.

[13] E. M. Molla, Chien-Hsun Liu, and Cheng-Chien Kuo, "Power quality improvement using microsystem technology for wind power plant," Microsystem Technologies, vol. 26, no. 6, pp. 1799-1811, 2020, doi: 10.1007/s00542-019-04726-3.

[14] R. Rezaei, P. Fromme, and P. Duffoura, "Fatigue Life Sensitivity of Monopile-Supported Offshore Wind Turbines to Damping," Renewable energy, vol. 123, pp. 450-59, August 2018, doi: 10.1016/j.renene.2018.02.086.

[15] L. Xionga, P. Li, M. Ma, Z. Wang, and J. Wang, "Output power quality enhancement of PMSG with fractional order sliding mode control," Electrical Power and Energy Systems, vol. 115, p. 105402, February 2020, doi: 10.1016/j.ijepes.2019.105402.

[16] P. He, R. Hong, H. Wang, and C. Lu, "Fatigue Life Analysis of Slewing Bearings in Wind Turbines," International Journal of Fatigue, vol. 111, pp. 233-242, 2018, doi: 10.1016/j.ijfatigue.2018.02.024.

[17] A. S. Bubshait, A. Mortezaei, M. G. Simões, and T. D. C. Busarello, "Power Quality Enhancement for a Grid Connected Wind Turbine Energy System," in IEEE Transactions on Industry Applications, vol. 53, no. 3, pp. 2495-2505, May-June 2017, doi: 10.1109/TIA.2017.2657482.

[18] F. Fateh, W. N. White, and D. Gruenbacher, "Torsional Vibrations Mitigation in the Drivetrain of DFIG-Based Grid-Connected Wind Turbine," in IEEE Transactions on Industry Applications, vol. 53, no. 6, pp. 5760-5767, Nov.-Dec. 2017, doi: 10.1109/TIA.2017.2730159.

[19] Fatih Kececioglu et al, "Power Quality Improvement Using Hybrid Passive Filter Configuration for Wind Energy Systems," $J$. Electr. Eng. Technol., vol. 12, no. 1, pp. 207-216, 2017, doi: 10.5370/JEET.2017.12.1.207.

[20] D. Giagopoulos, A. Arailopoulos, V. Dertimanis, C. Papadimitriou, E. Chatzi, and K. Giagopoulos, "Structural Health Monitoring and Fatigue Damage Estimation Using Vibration Measurements and Finite Element Model Updating," Structural Health Monitoring, vol. 18, no. 4, pp. 1189-1206, August 2018, doi: 10.1177/1475921718790188.

[21] X.-xing Yin, Yong-gang, and W. Li, "Modeling and loading compensation of a rotary valve-controlled pitch system for wind turbines," J. Zhejiang Univ. Sci. A, vol. 18, no. 9, pp. 718-727, 2017, doi: 10.1631/jzus.A1500072.

[22] B. Fitzgerald, A. Staino, and B. Basu, "Wavelet-Based Individual Blade Pitch Control for Vibration Control of Wind Turbine Blades," Structural Control and Health Monitoring, vol. 26, no. 1, p. e2284, 2018, doi: 10.1002/stc.2284.

[23] M. Moumna, R. Taleb, and Z. Boudjema, "Output voltage control of a PMSG with the DPC-SVM technique and high-order sliding mode," Indonesian Journal of Electrical Engineering and Computer Science, vol. 23, no. 2, pp. 772-781, August 2021, doi: 10.11591/ijeecs.v23.i2.pp772-781.

[24] M. A. Lilo and M. J. Mahammad, "Design and implementation of wireless system for vibration fault detection using fuzzy logic," IAES International Journal of Artificial Intelligence (IJ-AI), vol. 9, no. 3, pp. 545-552, September 2020, doi: 10.11591/ijai.v9.i3.pp545-552.

[25] L. F. Villa, A. Reñones, J. R. Perán, and L. J. de Miguel, “Angular resampling for vibration analysis in wind turbines under nonlinear speed fluctuation," Mechanical Systems and Signal Processing, vol. 25, no. 6, pp. 2157-2168, August 2011, doi: 10.1016/j.ymssp.2011.01.022.

[26] R. U. Maheswari and R. Umamaheswari, "Trends in non-stationary signal processing techniques applied to vibration analysis of wind turbine drive train - A contemporary survey," Mechanical Systems and Signal Processing, vol. 85, pp. 296-311, February 2017, doi: 10.1016/j.ymssp.2016.07.046.

\section{BIOGRAPHIES OF AUTHORS}
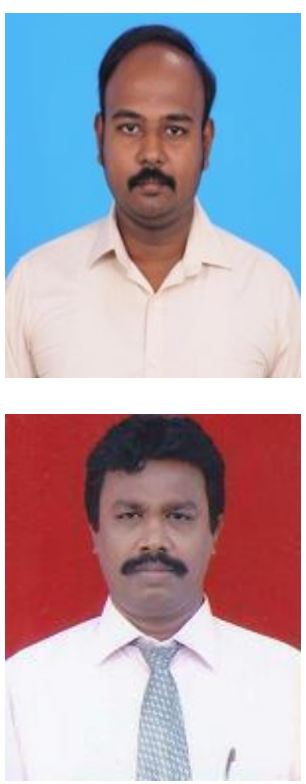

Anburaj Mutharasan (D) SC S P is a Research Scholar, Department of Electrical and Electronics Engineering, Vel Tech Rangarajan Dr. Sagunthala R\&D Institute of Science and Technology, Chennai. He also works as an Assistant Professor in the Department of Electronics and Communication Engineering, Vel Tech Rangarajan Dr. Sagunthala R\&D Institute of Science and Technology, Chennai. He obtained his Master's in M.Tech (Power Electronics) from Vel Tech Rangarajan Dr. Sagunthala R\&D Institute of Science and Technology, Chennai, in 2012. Areas of research Interest are Wind Energy Conversion System, Wind Turbine System, and Power Electronics. Life Member of ISTE and a Reviewer in reputed journals. He can be contacted at email: mutharasanm@gmail.com.

Perumal Chandrasekar (D) $\mathrm{SCC}$ P is a Professor, Department of Electrical and Electronics Engineering, Vel Tech Rangarajan Dr. Sagunthala R\&D Institute of Science and Technology, Chennai. He completed his Ph.D. in Power Quality monitoring and analysis, Anna University, Chennai. Research interests are Wavelet analysis and artificial intelligence to the power system, signal processing applications of power quality and reliability analysis, Image Processing, Renewable Energy, and Smart grid. He is having teaching experience of 22 years and associated with professional societies, likely ISTE and IEEE, USA, published 40 research papers in National and International conferences. He can be contacted at email: drchandrasekar@veltech.edu.in. 